
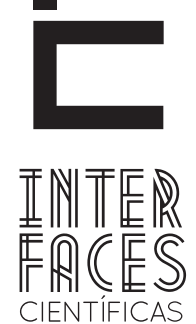

DIREITO

ISSN IMPRESSO 2316-3321

E - ISSN 2316-381X

DOI - 10.17564/2316-381X.2019v7n1p37-48

DOSSIÊ “30 ANOS DA CONSTITUIÇÃO FEDERAL: GANHOS, PERDAS E DESAFIOS EM MATÉRIA DE DIREITOS HUMANOS”.

\title{
A CONSTITUCIONALLZAC̄̃̃O DOS DIREITOS HUMANOS DAS MULHERES: 30 ANOS DE AVANÇOS FORMAIS EDESAFIOS PERSISTENTES
}

\author{
THE CONSTITUCIONALIZATION OF WOMEN'S HUMAN RIGHTS: 30 YEARS OF FORMAL ADVANCES AND PERSISTENTS CHALLENGES \\ LA CONSTITUCIONALZZACIÓN DE LOS DERECHOS HUMANOS DE LAS MUJERES: 30 AÑOS DE AVANCES FORMALES Y DESAFIOS PERSISENTES
}

Bianca Chetto Santos ${ }^{1}$

\section{RESUMO}

0 presente estudo surgiu a partir das investigações realizadas na disciplina Gênero e Poder do programa de pós-graduação do Núcleo de Estudos Interdisciplinares sobre Mulheres, Gênero e Feminismos da UFBA e traça o contexto iluminista dos marcos formais de advento dos direitos humanos das mulheres a partir de uma perspectiva feminista, analisando a constitucionalização desses preceitos na Carta Magna de 1988 por intermédio do movimento que ficou conhecido como "lobby do batom". Neste contexto, objetiva-se analisar as conquistas formais trazidas pela Constituição Federal de 1988 em matéria de direitos humanos para mulheres, bem como pontuar reflexões sobre a
Flávia Hardt Schreiner²

efetivação desses direitos na contemporaneidade por meio da análise das mudanças legislativas posteriores e de dados estatísticos recentes em um ensaio teórico desenvolvido a partir de revisão da bibliografia pertinente ao tema. Questiona-se, ao final, sobre os atuais obstáculos na efetivação desses direitos humanos das mulheres constitucionalizados há 30 anos.

\section{PALAVRAS-CHAVE}

Direitos Humanos das Mulheres. Constituição Federal. Efetivação dos Direitos Humanos. 


\section{ABSTRACT}

The present study was motivated by the studies carried out in the discipline Gender and Power of the postgraduate program of the Núcleo de Estudos Interdisciplinares sobre Mulheres, Gênero e Feminismos at UFBA and aims to trace the Iluminist context that originate the women's human rights from a feminist perspective, analyzing the constitutionalization of these precepts in the 1988 Constitution through the movement known as "Lobby do batom". The goal is to analyze the formal achievements brought by the Federal Constitution of 1988 in terms of human rights for women, as well as to reflect on the realization of these rights in the contemporary world through the analysis of the subsequent legislative changes and recent statistical data in an essay from a review of the literature relevant to the topic. At the end, we question the current obstacles in the implementation of these human rights of women constitutionalized 30 years ago.

\section{KEYWORDS}

Women's humans rights. Federal Constitution. Implementation of Human Rights.

\section{RESUMEN}

El presente estudio surgió a partir de las investigaciones realizadas en la disciplina Género y Poder del programa de post graduación del Núcleo de Estudos Interdisciplinares sobre Mulheres, Gênero e Feminismos de la UFBA y traza el contexto iluminista de los marcos formales de advenimiento de los derechos humanos de las mujeres desde una perspectiva feminista, analizando la constitucionalización de esos preceptos en la Carta Magna de 1988 por intermedio del movimiento que se conoció como "lobby do batom". En este contexto, se pretende analizar las conquistas formales aportadas por la Constitución Federal de 1988 en materia de derechos humanos para mujeres, así como puntuar reflexiones sobre la efectividad de esos derechos en la contemporaneidad a través del análisis de los cambios legislativos posteriores y de datos estadísticos recientes en un ensayo teórico desarrollado a partir de la revisión de la bibliografía pertinente al tema. Se cuestiona, al final, sobre los actuales obstáculos en la efectividad de esos derechos humanos de las mujeres constitucionalizados desde hace 30 años.

\section{PALABRAS CLAVE}

Derechos humanos de las mujeres. Constituicion Federal. Eficacia de los derechos humanos. 


\section{INTRODUÇ̄̃̃O}

Em outubro de 2018 a Carta Magna completa três décadas e se torna impossível não recordar do contexto do país à época da Assembleia Constituinte como uma República Federativa que saiu de um silêncio de 21 anos do regime militar. A Constituição Federal de 1988 abriu um espaço para uma reafirmação dos direitos humanos e para a consagração de um verdadeiro Estado Democrático de Direito.

A participação das mulheres durante a ditadura e no momento de transição democrática foi fundamental. Muitos direitos fundamentais foram pleiteados e conquistados pelo movimento feminista no contexto da Assembleia Constituinte, sendo o princípio da igualdade preceito central dessas conquistas, materializado no artigo $5^{\circ}$ inciso I da Constituição Federal (SILVA, 2008, 2012)1. Trinta anos depois, a discriminação social e a violência contra a mulher ainda presentes em nossa sociedade sugerem que a igualdade conquistada entre mulheres e homens não se materializou em mudanças concretas.

A contínua criação de legislações específicas para as mulheres e a intensa organização dos movimentos feministas para efetivação de direitos ligados à dignidade da pessoa humana por meio de políticas públicas são pistas de algumas reflexões sobre o quanto as mulheres ainda precisam caminhar na efetivação de seus direitos. Nesta toada, o presente ensaio analisa o surgimento dos direitos humanos e sua extensão tardia às mulheres, pensando criticamente, em seguida, as pautas defendidas e conquistadas pelos movimentos feministas na Constituição de 1988 para verificar a eficácia desses direitos.

Assim, foi realizada revisão bibliográfica sobre a constitucionalização dos direitos humanos das mulheres e o chamado lobby do batom, bem como o estudo dos direitos reivindicados pelas mulheres na carta apresentada pelo Conselho Nacional dos Direitos da Mulher (CNDM) à Constituinte e sua consagração no texto original da Constituição Federal de 1988 (SILVA,

1 Art. $5^{\circ}$, I: homens e mulheres são iguais em direitos e obrigações, nos termos desta Constituição (BRASIL, 1988).
2008, 2012). Em seguida, tomando por pressuposto o caráter bivalente das coletividades discriminadas por gênero ou raça (ou ambos) e a necessidade de uma justiça bidimensional que atenda tanto às demandas por redistribuição econômica quanto àquelas por reconhecimento cultural (FRASER, 2001), investiga-se de que maneira os direitos humanos das mulheres constitucionalizados em 1988 foram efetivados nas décadas seguintes por meio da análise do caráter afirmativo ou transformativo das legislações e políticas públicas deles decorrentes e, quando possível, da sua concretização em termos estatísticos.

0 questionamento motivador desses ensaios é a própria pertinência dos direitos humanos como foco de reivindicações concretas para mulheres, mote despertado pelos estudos realizados na disciplina Gênero e Poder do programa de pós-graduação do Núcleo de Estudos Interdisciplinares sobre Mulheres, Gênero e Feminismos da Universidade Federal da Bahia (UFBA), cursada pelas autoras.

\section{ECLOSÃO DOS DIREITOS HUMANOS DAS MULHERES NO CONTEXTO ILUMINISTA}

Desde o século XIX, o movimento feminista é reconhecido por meio de seu processo crítico que recai sobre muitos registros incontestes da história humana e sobre pressupostos básicos das ciências modernas. A crítica feminista à ciência como conhecemos hoje tem suas raízes históricas no próprio lluminismo (SARDENBERG, 2002). 0 chamado "século das luzes" formou a base da filosofia e da prática política liberal da modernidade, a qual reatualizou o trio dos valores "revolucionários" burgueses de liberdade, igualdade e fraternidade, forjando-os na própria ideia de democracia ocidental atual (PETIT, 1994).

A fim de compreender as influências androcentradas dessa Teoria Política e do Direito Moderno, que é sua expressão, configura-se um desafio articular, dentro da perspectiva feminista, os elementos históricos-sociais presentes nas teorias contratualistas. Segundo Petit (1994, p. 36), essas teorias, tão pre- 
sentes nos estudos da filosofia jurídica, surgiram no contexto Iluminista como única justificação possível para a existência de um Estado ou um corpo político que poderia deslocar o homem livre (e não a mulher) da natureza, alinhando-o à sociedade civil.

$O$ contrato social objetivou regular a sociedade da época, atingindo a sua plenitude no século XVIII e é teorizado por filósofos já conhecidos como Immanuel Kant, John Locke e Jean-Jacques Rousseau. Para este último jusnaturalista, as mulheres deveriam ser educadas na reclusão sexual e castidade que legitimam a paternidade, estimular o desejo masculino e ao mesmo tempo impedir a lascívia dos homens (NYE, 1995, p. 20). Destarte, para Pateman (1993), o contrato original advinha de uma ordem social patriarcal em que a diferença sexual era também política, o contrato era social-sexual e legitimava a sujeição/dominação das mulheres: meros objetos desse contrato.

Essa ordem social patriarcal está presente em várias sociedades, não havendo motivos (nem meios) que justifiquem ser epistemologicamente necessário determinar suas origens. 0 que se torna importante frisar é que existiram (e existem) diferentes lógicas patriarcais em diferentes sociedades e momentos históricos da humanidade. 0 que essas lógicas têm em comum é que elas invariavelmente nos remetem, de alguma maneira, às ideias de poder, autoridade e controle (DAHLERUP, 1987). O patriarcado, portanto, não é natural nem meramente universal, mas sim cultural (DAHLERUP, 1987), de maneira que a subordinação das mulheres assume diversas nuances.

A visão jusnaturalista e androcentrada presente no contrato social é inerente ao processo de mudança histórica que vai integrar a Revolução Francesa (PATEMAN, 1983), a qual consagrou as premissas básicas da ciência jurídica. O Direito Moderno desenvolve-se a partir dos princípios Iluministas de primazia do indivíduo e sua liberdade enquanto atributo masculino (e universal), liberdade esta que caracteriza a própria existência humana. Os direitos fundamentais do homem, a separação de poderes e a supremacia do Estado ganham caráter formal nesse contexto histórico. Ou seja, o direito natural do século XVIII funda um sistema que se chamaria, num primeiro momento, direitos do homem e, mais tarde, direitos humanos.

O surgimento do conceito de direitos humanos como parte dessa tradição iluminista surge de forma excludente. Neste cenário político racionalista, individualista, liberal e androcêntrico, também se desenvolvem as primeiras reivindicações políticas organizadas do movimento feminista2, as quais, nesse período paradoxal, avocaram os direitos fundamentais para as mulheres ligados à educação, à vida pública, ao emprego e ao afamado direito ao voto.

Em 1789, a "Declaração dos direitos do homem e do cidadão" reconheceu a igualdade de direitos dos indivíduos à liberdade, à propriedade, à segurança, à resistência e à opressão. Em 1791, a francesa Olympe de Gouges apresentou sua “Declaração da mulher e da cidadã" 3 em resposta ao documento de 1789, pois restava claro que, desde aquela época, o exercício dos direitos naturais da mulher não tinha outros limites senão aquele que a tirania perpétua do homem opõe a eles (NYE, 1995). Nessa linguagem universalista, típica do direito natural, o "indivíduo" de que tratava a Declaração Francesa, não era, de fato, a mulher.

De acordo com Flávia Piovesan (2009), a concepção contemporânea dos direitos humanos foi introduzida com a Declaração Universal de 1948, marcada pela universalidade e indivisibilidade destes direitos, orientada pela afirmação da dignidade e pela prevenção ao sofrimento humano dentro do contexto de pós-guerra. Ao longo da história as mais graves violações aos direitos humanos tiveram como fundamento a dicotomia do "eu versus o outro", em que a diversidade era captada como elemento para aniquilar direitos. 0 temor à diferença é fator que permite compreender a primeira fase de

2 Essa premissa é sempre colocada com ressalvas, pois ainda que a história dos direitos humanos remeta invariavelmente para registros hegemônicos, autoras como Sonia Alvarez (2014) e Ochy Curiel (2009), deixam claro que o movimento feminista não branco vai além da Europa e do contexto da Revolução Francesa na luta pelos seus direitos e na oposição ao patriarcado, como no texto de Curiel "Descolonizando el feminismo: una perspectiva desde America Latina y el Caribe.

$3 \mathrm{Na}$ Inglaterra, ver a Vindication of the Rights of Woman de Mary Wollestonecraft de 1792. 
proteção dos direitos humanos, marcada pela tônica da proteção geral e abstrata, com base na igualdade formal (PIOVESAN, 2009, p. 78).

Nessa concepção, a diferença era utilizada para segregar e hierarquizar os seres humanos, justificando as violações de direitos cometidas nesse período. Desta maneira, a construção histórica dos direitos humanos forçosamente incorporou uma universalidade abstrata. Ao mesmo tempo, esse mesmo Estado pós-guerra organizou uma cultura política que visualizava o cidadão de tipo ideal como um trabalhador masculino pertencente à maioria étnica (branca), chefe e homem de família, responsável principal pelo sustento financeiro do lar. Esse ideal do "patriarca" nesse período definiu normas de gênero e disciplinou quem as subvertia (FRASER, 2009).

Logo, a proteção geral e abstrata, dentro de uma linguagem aparentemente neutra e universal dos direitos humanos, resguarda uma tutela frágil da dignidade da pessoa humana. Tratar o "ser humano" de forma genérica acaba por excluir mulheres, crianças, populações afrodescendentes e demais categorias vulneráveis, privilegiando homens brancos e de classes abastadas como seres humanos por excelência. Nesse sentido, o acesso a direitos humanos para mulheres exige remédios afirmativos de suas diferenças, dialogando diretamente com políticas de reconhecimento.

No entanto, como pontua Fraser (2001), as mulheres compõem uma categoria bivalente. Significa dizer, portanto, que a subversão de sua subjugação histórica pelas ordens patriarcais também impõe a necessidade de redistribuição de bens e recursos econômicos. Assim, em que pese sejam relevantes as ações de caráter afirmativo para a resolução de injustiças imediatamente (ou tanto quanto possível), são as políticas transformativas que, desestabilizando o status quo, tem potencial para a resolução das discrepâncias de poder entre mulheres e homens a longo prazo. Importa destacar que as políticas redistributivas podem ser tanto afirmativas quanto transformativas, conforme elucida Fraser (2001), a depender da sua finalidade. Enquanto os remédios afirmativos têm por objetivo corrigir os efeitos ar- ranjos sociais desiguais, os transformadores visam a reconfiguração desses arranjos desde as estruturas.

$\mathrm{Na}$ esfera dos direitos humanos, os preceitos fundamentais de liberdade e (principalmente) igualdade poderiam - em tese - ser tensionados tanto para a realização de ações afirmativas quanto transformativas. Isto porque tanto os remédios afirmativos, quanto os transformativos, pressupõem uma concepção universalista e deontológica do valor moral igual das pessoas para construir suas reivindicações (FRASER, 2001, p. 217). No entanto, olhando para a conformação histórica liberal dos direitos humanos e considerando a manutenção da ordem social como função precípua do próprio Direito positivo, é preciso questionar se políticas transformativas realmente podem ser concretizadas a partir dessa seara.

\section{LOBBYDO BATOM E OS MOVIMENTOS PELA CONSTITUCIONALIZAÇÃO DOS DIREITOS DAS MU- LHERES NO BRASIL}

A Constituição Federal de 1988 não poderia fugir à principiologia iluminista ou à demanda neoliberal. Os regimes antidemocráticos estatuídos no país entre 1937 e 1945 e entre 1964 e 1985 interromperam a concretização dos direitos humanos no Brasil. Assim, é após a abertura democrática e com a ebulição dos movimentos sociais que ganharam força nos anos finais da ditadura militar, que a pauta dos direitos humanos consolida sua força, assumindo posição central na constituinte.

Se os direitos humanos foram impulsionados no pós-ditadura, a pauta do desenvolvimento também ganha força graças ao avanço neoliberal na conjuntura internacional que culminará no Consenso de Washington em $1990^{4}$. Desde a proclamação da Década da

40 Consenso de Washington constitui uma série de recomendações de caráter neoliberal para o combate das crises e misérias dos países subdesenvolvidos, realizadas pelo economista estadunidense John Williamson. Essas medidas que serão adotadas pelo FMI e impostas como requisitos obrigatórios aos países latino-americanos que requerem auxílio econômico e negociação de suas dívidas externas (NOGUEIRA, 1999). 
Mulher da Organização das Nações Unidas (ONU), em 1975, o desenvolvimento se tornou um grande agente facilitador dos movimentos de mulheres pelo mundo, intensificando uma relação ambígua com os movimentos feministas como resgata Alvarez (2014). Ao tempo que impulsiona pautas de mulheres, o neoliberalismo atrelado à agenda desenvolvimentista também higieniza e exerce controle sobre essas pautas, o que, entre outros fatores, implicará na formulação das demandas à serem pleiteadas pelos movimentos feministas na constituinte e na receptividade destas pelas congressistas eleitas e demais integrantes da assembleia.

A criação do CNDM, em 1985, é fruto dos tensionamentos entre o princípio da autonomia em relação ao Estado, tão cara aos movimentos feministas no Brasil até então e a possibilidade, inexistente durante o regime militar, de ocupar espaços institucionais e participar da elaboração e direcionamento das políticas públicas. Pimenta (2010) relembra as divergências que surgem no seio dos movimentos feministas neste período: enquanto algumas feministas estavam dispostas a atuar diretamente nas estruturas institucionais, ocupando cargos públicos, outras pretendiam se manter autônomas e dirigiam duras críticas às companheiras. Uma terceira parcela das ativistas se mantinham na intersecção destes dois campos, oferecendo apoio às feministas “institucionalizadas" sem, contudo, ocuparem diretamente os espaços estatais.

O principal objetivo do Conselho era o de "promover a liberdade, a igualdade de direitos e a plana participação das mulheres em âmbito nacional” (PIMENTA, 2010 p. 77). A atuação neste sentido começa desde a sua criação com a realização de campanhas em todo país para a candidatura de mulheres às eleições que ocorreriam no ano seguinte e para a inclusão de direitos relacionados às mulheres na Constituição, sob o lema "Constituinte pra Valer tem que ter palavra de mulher” (TABAK, 1989; PIMENTA, 2010; SILVA, 2008, 2012).

O processo de sensibilização e conscientização de parlamentares à respeito das pautas feministas e de mulheres ficou conhecido como "lobby do batom" . 5 Pimenta (2010, p. 91) pontua que o termo "lobby do batom" foi uma classificação feita por alguns parlamentares valendo-se de um recurso irônico como uma tentativa de inferiorizar ou, até mesmo, ridicularizar as manifes-
O trabalho de convencimento foi realizado por movimentos feministas e de mulheres, muitas filiadas a sindicatos, por trabalhadoras domésticas e rurais, bem como por estudantes e pelas integrantes do CNDM com o intuito de garantir a inserção dos direitos das mulheres na nova Constituição (PIMENTA, 2010; PITANGUY, 2012).

Foram eleitas 26 mulheres para compor a Assembleia Nacional Constituinte de dezesseis estados diferentes e nove partidos políticos ${ }^{6}$. No que diz respeito às pautas de interesses das mulheres, o CNDM recebeu centenas de propostas da sociedade civil que foram analisadas por uma equipe técnica e por uma comissão voluntária de mulheres advogadas. 0 resultado foi a elaboração da “Carta das Mulheres Brasileiras aos Constituintes”, entregue ao deputado Ulysses Guimarães, então Presidente do Congresso Nacional (SILVA, 2012).

Para além de trazer disposições exclusivamente atinentes às mulheres, como ressalta Silva (2008), o lobby do batom também reivindicou direitos pertinentes à população negra, pessoas com deficiência, pessoas idosos, presidiários/as, crianças e adolescentes. Merecem destaque, nesse sentido, o pleito por aposentadoria especial para trabalhadores e trabalhadoras rurais; igualdade entre filhos(as) havidos dentro e fora do casamento; coibição legal do abandono de menores; licença-paternidade durante e logo após a gestação da mãe; proteção à velhice (de homens e mulheres); direito do marido ou companheiro de usufruir dos benefícios previdenciários de esposas ou companheiras; eliminação de idade limite para prestação de concurso público; direito de sindicalização para funcionários públicos; criação de um Sistema Único de Saúde implementado por serviços públicos de saúde coletiva e assistência médica integrada; obrigatoriedade do ensino da história da África e cultura afro-brasileira desde a educação básica; reforma agrária com distribuição de terra aos trabalhadores e trabalhadoras que nela trabalham; reforma tributá-

tações das mulheres no processo constituinte.” As mulheres se apropriaram do nome, atribuindo nova conotação.

6 "As 26 mulheres da constituinte foram eleitas por nove diferentes partidos políticos: PMDB (11), PFL (6), PT E PDS (2 cada); PDT, PSB, PSC, PTB E PC do B (uma deputada cada um)", conforme destaca Tabak (1989, p. 142). 
ria que beneficie os municípios (BRASIL, 1987); todos presentes na carta entregue à Constituinte pela CNDM, demonstrando o seu caráter democrático e de abrangência interseccional.

\section{ANOSDECONSTITUIÇ̃̃ODEMOCRÁTICA:ENTRE AVANÇOS FORMAIS EVIOLAÇ̃ES PERSISTENTES}

O lobby do batom teve sucesso na inclusão de $80 \%$ das pautas apresentadas ao parlamento constituinte (SILVA, 2012). As chamadas "reivindicações específicas" constantes na carta das Mulheres propunha inovações e alterações legislativas que envolviam eixos temáticos assim intitulados: família, trabalho, saúde, educação e cultura, violência e questões nacionais e internacionais. O principal fundamento norteador dessas demandas foi a "igualdade".

Esse mesmo preceito, considerando a invocação do valor moral igual de todas as pessoas como característica comum entre demandas por reconhecimento e por redistribuição, pode ser acessado para fundamentar o direito à políticas transformativas e afirmativas. No entanto, não se pode perder de vista que o princípio da igualdade tem sua origem no lluminismo e possui posição central nas agendas neoliberais em favor das mulheres. Talvez por esta razão grande parte das demandas pleiteadas e conquistas pelas mulheres em 1988 tem, em verdade, conotação simbólica: reconhecer as mulheres enquanto sujeitos de direitos humanos.

$\mathrm{Na}$ contrapartida, o potencial transformativo das reivindicações presentes na carta das mulheres perde fôlego, sendo não apenas contemplados em menor grau pela Constituinte, como principalmente pelas legislações e políticas públicas implementadas nas décadas seguintes, que seriam essenciais para a sua efetivação. Essa observação converge com a análise realizada por Silva (2012), que aponta para a necessidade de compreensão da teoria da Constituição como uma ciência da cultura, de modo que a efetivação dos direitos constitucionais será limitada pelas tensões sociais.
O primeiro plano de demandas, tomando por base os eixos temáticos elencados na carta das CNDM, diz respeito às relações familiares e ao âmbito privado. Além de estabelecer a igualdade no já mencionado art. $5^{\circ}$, inciso I a Constituição também determinando expressamente a igualdade de direitos e obrigações entre homens e mulheres diante do casamento e dos filhos no art. 226, § $5^{\circ}$.

A proclamação da igualdade de direitos e obrigações entre homens e mulheres no âmbito privado e na família é uma demanda por reconhecimento que possui caráter evidentemente transformativo. Todavia, para ir além do plano formal, ela exige a consolidação de políticas públicas e a articulação com outros direitos (FONTES, 2013), como por exemplo, a licença-paternidade, pleiteada pelo lobby do batom. Entretanto, a previsão constitucional obtida foi de licença-paternidade de apenas 5 dias o que evidencia o grau de naturalização do papel da mãe como reprodutora e cuidadora e dilui o potencial transformativo desses direitos.

Apesar de, em março de 2016 a presidenta Dilma Rousseff ter sancionado a Lei 13.257/2016 que amplia a licença-paternidade para 20 dias em casos específicos ligados ao projeto Empresa Cidadã, os prazos constitucionalmente distintos e discrepantes para a licença-paternidade e a licença-maternidade, na prática, dificultam que o genitor possa participar mais ativamente na maternidade, consolidando papéis de gênero historicamente questionados.

Outra pauta conquistada pelo lobby foi o acesso da mulher rural à titularidade de terras em Planos de Reforma Agrária, demanda que tem óbvia natureza redistributiva e transformadora. 0 título do domínio urbano, em seu art. $183, \S 1^{\circ}$, garante a concessão de uso ao homem ou à mulher, ou a ambos, independentemente do estado civil. 0 art. 189 trata dos beneficiários da distribuição de imóveis rurais pela reforma agrária e também garante títulos de domínio ou de concessão de uso (inegociáveis pelo prazo de dez anos) ao homem ou à mulher, ou a ambos, independentemente do estado civil.

Essa conquista do direito a um título de posse na Constituição e pelo Programa Nacional de Reforma 
Agrária foi concretizado em 2007, por meio da Instrução Normativa 38, do Instituto Nacional de Reforma Agrária (INCRA), pois as mulheres chefes de família passaram a ter direito preferencial à terra. Todavia, em termos práticos, é possível dizer que essa conquista teve maior eficácia do ponto de vista simbólico-afirmativo do que transformador, em que pese o seu potencial para a desestabilização do status quo.

Isto porque de acordo com o Plano Nacional de Política para as Mulheres 2013-2015 (SPM, p. 66$67)$ ainda há muitos entraves na política de Reforma Agrária para as mulheres, principalmente para segmentos que vivem sob condições distintas, como quilombolas e indígenas. Os embaraços concernentes à demarcação de áreas rurais para comunidades específicas ou o acesso à documentação básica para garantir a posse e o domínio de terras são exemplos dos obstáculos ainda enfrentados.

No que diz respeito à tutela das relações de trabalho, outro eixo temático presente na carta de reivindicações, a redação do artigo $7^{\circ}$, inciso XX da Constituição Federal consagrou a proteção do mercado de trabalho da mulher, mediante incentivos específicos (a serem definidos em lei posterior) como o direito da mulher trabalhadora urbana e rural. No inciso $X X X$ proibiu-se expressamente a diferença de salários, de exercício de funções e de critério de admissão por motivo de sexo, idade, cor ou estado civil. Tais disposições do texto de origem evidenciaram à época o reconhecimento formal de que existiam, de fato, situações de desigualdade que privilegiavam os homens quanto ao acesso e as condições de trabalho e, principalmente, quanto à igualdade salarial.

Porém, desde 1988 até os dias atuais, o desafio continua no campo da concretização desses direitos sociais do ponto de vista redistributivo, como bem pontuou Fraser, pois no plano da realidade, a contestação e o enfrentamento dessas desigualdades são cotidianos. 0 estudo do Instituto de Pesquisa Econômica Aplicada (IPEA) sobre as desigualdades de gênero e raça nos últimos 20 anos mostrou que no mercado de trabalho, a maior parte dos indicadores apontam para uma hierarquia estanque, na qual 0 topo é ocupado pelos homens brancos e a base pelas mulheres negras (IPEA, 2016, p. 2). O estudo também mostrou que, além de as mulheres trabalharem, em média, sete horas e meia a mais que os homens por semana e estudarem mais, continuam recebendo menores salários ${ }^{7}$.

Ainda na guarda dos direitos sociais, o texto original do inciso XVIII do artigo $7^{\circ}$ protegeu a maternidade, ampliando a licença para cento e vinte dias sem prejuízo do emprego e do salário. Também foi concedida a estabilidade no emprego até 5 meses após o parto no texto do Ato das Disposições Constitucionais Transitórias. No campo do reconhecimento, a posterior legislação 12.873/2013 amparou as relações familiares historicamente excluídas da tutela constitucional, como os casais homoafetivos, estendendo a concessão da licença-maternidade a estes, o que não havia sido pautado pelo lobby feminista à época da constituinte.

O eixo temático seguinte diz respeito à saúde e inclui a demanda sobre os direitos sexuais e reprodutivos das mulheres, pauta quase unânime dos movimentos feministas, em particular, a garantia ao aborto seguro e gratuito. A Pesquisa Nacional de Aborto (PNA) realizada em 2016 (PNA, 2016) revelou que 1 em cada 5 mulheres brasileiras, aos 40 anos, já realizou, pelo menos um aborto e que cerca de metade dessas mulheres foram internadas no sistema público de saúde devido a complicações médicas (a maioria, negras) (PNA, 2016, p. 653). A esfera de ilegalidade de quem aborta se transformou em um dos maiores problemas de saúde pública do Brasil (PNA, 2016, p. 659).

No contexto da Constituinte, conquistou-se o direito de debater formalmente no plano político e jurídico sobre a legalização do aborto. Porém, as resistências oferecidas pela maioria dos constituintes à época hoje reproduzem-se na atuação política parlamentar conservadora. A noção de que a vida se inicia na concep-

7 Ressalta-se que a recente Reforma Trabalhista (Lei 13.467/2017), potencializa a precarização do trabalho de toda gente, atingindo principalmente às populações socialmente mais vulneráveis, como, por exemplo, as mulheres negras, reflexão esta de extrema importância, mas que não é objeto do presente artigo. 
ção é um elemento fundamental na visão que funda o discurso contrário ao direito ao aborto (BIROLI, 2017).

A recente Proposta de Emenda Constitucional (PEC) 181/2015 que, apesar de versar sobre a extensão da licença-maternidade em caso de parto prematuro, foi alterada para incluir a controversa expressão "desde a concepção" na Constituição. No inciso III do artigo $1^{\circ}$ que trata dos princípios fundamentais da República, a redação seria alterada para "dignidade da pessoa humana desde a concepção". E, o artigo $5^{\circ}$, que garante a igualdade de todos perante a lei, seria transcrito para "a inviolabilidade do direito à vida desde a concepção".

Em 2018, a deliberação desta proposta continuará em meio a influência religiosa institucional junto à opinião pública que tem reposicionado as forças políticas mais conservadoras (BIROLI, 2017). Dessa maneira, questiona-se a abertura de brechas para uma proibição total do aborto no Brasil, até nos casos atualmente permitidos por lei, violando a autonomia reprodutiva da mulher, a qual fundamenta-se nos direitos à dignidade, igualdade, liberdade e privacidade previstos nos artigos art. $1^{\circ}$ e $5^{\circ}$ da Constituição Federal.

No que diz respeito às demandas em torno da educação, pleiteadas pelas mulheres na constituinte, os preceitos evocados também possuíam força transformadora no campo do reconhecimento: "a educação dará ênfase à igualdade entre os sexos, à luta contra o racismo e todas as formas de discriminação", lia-se na carta da CNDM (1987, p. 4). A Constituição Federal de 1988 acolheu algumas das pautas relacionadas à Educação, como por exemplo que o ensino da História do Brasil deve levar em conta "a contribuição das diferentes culturas e etnias para formação do povo brasileiro"8 e os movimentos feministas conseguiram, nos anos 1990 a inclusão da temática de gênero nos Parâmetros Curriculares Nacionais do Ensino Fundamental. As pautas em torno da educação são essencialmente transformadoras, levando à maior dificuldade em sua concretização.

8 Art. $242 \S 1^{\circ}$ da Constituição Federal. Essa disposição constitucional implica na sanção de dispositivo legal na Lei de Diretrizes e Bases da Educação que "inclui no currículo oficial da Rede de Ensino a obrigatoriedade da temática História e Cultura Afro-Brasileira" (Lei 10.639/2003), fruto de reivindicações dos movimentos negros.
A Base Nacional Comum Curricular foi aprovada em 2017 sem a discussão de temas como os relacionados a gênero e orientação sexual, retiradas por determinação do próprio Ministério da Educação. Há ainda o Projeto de Lei 7180/14, conhecido como "Escola sem partido" que prevê a proibição do desenvolvimento de políticas de ensino ou oferta de disciplinas, mesmo que optativas, que tratem sobre "gênero" ou "orientação sexual".

0 eixo da violência, por sua vez, apresenta demandas de caráter afirmativo e também transformador. No art. $226 \S 8^{\circ}$ é assegurada a assistência à família na pessoa de cada um dos que a integram e imposta ao Estado a obrigação de criar mecanismos para coibir a violência no âmbito de suas relações. Quase todas as doze pautas elencadas pelas mulheres na carta da CNDM (1987, p. 5-6), estão previstas em lei ou atos normativos atualmente, em que pese nem todas tenham sido contempladas expressamente na Constituição Federal.

De fato, muitas das demandas correspondiam a matérias pertinentes ao Código Penal. Assim, as alterações pleiteadas em relação ao crime de estupro, passando a integrar qualquer ato ou relação sexual forçada independente do relacionamento existente entre agressore vítima, a penalidade semelhante entre atentado violento ao pudor e conjunção carnal (que hoje constituem o mesmo tipo), a retirada do termo "mulher honesta" e a configuração dos crimes sexuais como atentatórios à pessoa e não aos "costumes" são algumas das conquistas que só foram obtidas anos depois 9 .

A reivindicação de Delegacias de Especializadas de Atendimento à Mulher em todos os municípios do país segue sem implementação, presente apenas em algumas cidades brasileiras. 0 mesmo vale para a exigência de que o Estado crie e mantenha casas de abrigo para mulheres em risco de morte, em que pese conste como uma das prioridades para o atendimento no Plano $\mathrm{Na}$ cional de Políticas para Mulheres e na Lei Maria da Penha, só existe em 130 municípios (IBGE, 2009).

A manutenção de casas de abrigamento, o recrudescimento punitivo e o acompanhamento psicoló-

9 Essas alterações foram feitas ao Código Penal pelas leis 11.106/2005 e 12.015/09. 
gico de mulheres vítimas de violência tem extrema importância a curto prazo e constituem medidas de urgência necessárias, todavia, não significam respostas a longo prazo contra a reprodução da violência contra a mulher, a qual também perpassa pela economia política (FONTES, 2013).

A Lei Maria da Penha, grande marco legislativo do combate à violência doméstica, institui um programa de políticas públicas integrado, nas áreas da saúde, assistência social, psicologia, previdência, entre outras, para o enfrentamento da violência (doméstica) contra a mulher, retirando a questão da esfera exclusivamente criminal (FONTES, 2013). Não existe, no entanto, qualquer política pública que garanta efetivamente o exercício do à educação, cultura, moradia e trabalho, também previstos na Lei pelas mulheres em situação de violência.

\section{CONCLUSÃO}

As reivindicações pautadas pelos movimentos feministas e de mulheres à época da Constituinte e formalizadas pela CNDM tiveram por base a noção de igualdade, princípio de origem iluminista e visavam a consolidação de ações que poderiam ser compreendidos tanto do ponto de vista da redistribuição, quanto do reconhecimento.

Como demonstrado, o lobby do batom foi considerado bem sucedido na medida em que conseguiu formalizar a maior parte de suas demandas no texto original da Carta Magna. Todavia, a análise realizada neste ensaio, considerando a origem liberal e androcentrada dos Direitos Humanos e as influências e resistências neoliberais e desenvolvimentistas presentes desde a constituinte até os dias atuais, demonstra que as repercussões práticas das demandas formalmente conquistadas encontraram e encontram diversos obstáculos. 0 plano de concretização dos direitos humanos das mulheres é facilitado em torno de remédios afirmativos, mas encontra maior resistência quando das tentativas de implementação de políticas com caráter transformativo.

\section{REFERÊNCIAS}

ALVAREZ, Sonia E. Engajamentos ambivalentes, efeitos paradoxais: movimentos feminista e de mulheres na América Latina e/em/contra o desenvolvimento. Revista Feminismos, v. 2, n. 1, 2014.

BIROLI, F; MARIANO, R; MIGUEL, L. O direito ao aborto no debate legislativo brasileiro: a ofensiva conservadora na Câmara dos Deputados.

Opinião Pública, v. 23, n. 1, p. 230-260, 2017. Disponível em: http://www.redalyc.org/articulo. oa?id=3295043900 $>$. Acesso em: 15 jul. 2018.

BRASIL. Conselho Nacional de Direitos das Mulheres.

Carta das mulheres brasileiras aos constituintes de 1987. Disponível em http://www2.camara.leg. br/atividade-legislativa/legislacao/Constituicoes_ Brasileiras/constituicao-cidada/constituintes/aconstituinte-e-as-mulheres/Constituinte $\% 20$ 1987-1988-Carta\%20das\%20Mulheres\%20aos\%20 Constituintes.pdf. Acesso em: 1 ago. 2018.

\section{BRASIL. Constituição da República Federativa do}

Brasil de 1988. Disponível em: http://www. planalto. gov.br/ccivil_03/constituicao/constituicaocompilado. htm. Acesso em: 15 jul. 2018.

BRASIL. Secretaria de Políticas para as Mulheres (SPM). Presidência da República. Plano Nacional de Políticas para as Mulheres. Brasília: Secretaria de Políticas para as Mulheres, 2013. 114p. Disponível em: http://www. spm.gov.br/assuntos/pnpm/publicacoes/pnpm-20132015-em-22ago13.pdf. Acesso em: 25 jul. 2018.

BRASIL. Câmara dos Deputados. Projeto de Lei n. 7180/14. Disponível em: http://www.camara.gov. br/proposicoesWeb/fichadetramitacao?idProposic ao $=606722$. Acesso em: 1 ago. 2018.

BRASIL. Conselho Nacional de Educação. Base

Nacional Comum Curricular de 2017. Disponível em: 
http://basenacionalcomum.mec.gov.br/downloadda-bncc. Acesso em: 15 jul. 2018.

CURIEL, Ochy. Descolonizando el feminismo: una perspectiva desde America Latina y el Caribe. 2009. Disponível em: http://feministas.org/IMG/pdf/Ochy_ Curiel.pdf. Acesso em: 1 ago. 2018.

DAHLERUP, Drude. Conceptos confusos. Realidad confusa: una discusión teórica sobre el Estado patriarcal. In: SASSOON, Anne (org.) Las mujeres y el Estado. Madrid: Vindicación Feminista, 1987. p.111-150.

FRASER, Nancy. Da redistribuição ao reconhecimento? Dilemas da justiça na era póssocialista. In: Democracia hoje: novos desafios para a teoria democrática contemporânea. Brasília: Editora Universidade de Brasília, 2001. p. 245-282.

FRASER, Nancy. O feminismo, o capitalismo e a astúcia da história. Mediações,

Londrina, v. 14, n.2, jul./dez. 2009, p.11-33.

FONTES, Rafaela S. A construção do conceito de direitos humanos das mulheres no âmbito das organizações supra-nacionais de proteção aos direitos humanos e a sua respectiva influência na promulgação da Lei Maria da Penha. In.: WOLKMER, Antonio Carlos; CORREAS, Oscar. Crítica jurídica na América Latina. CENEJUS, 2013. p. 784-805.

IPEA - Instituto de Pesquisa Econômica Aplicada. Retrato das desigualdades de gênero e raça. Brasília, 2016. Disponível em: http://www.ipea.gov.br/portal/images/ stories/PDFs/170306_retrato_das_desigualdades_de_ genero_raca.pdf. Acesso em: 20 jul. 2018.

NOGUEIRA, Paulo B. 0 consenso de Washington: a visão neoliberal dos problemas latino-americanos. 1999. NYE, Andrea. Teoria feminista e as filosofias do homem. Rio de Janeiro: Rosa dos Tempos, 1995. PATEMAN, Carole. 0 contrato sexual. Rio de Janeiro: Paz e Terra, 1993.
PETIT, Cristina Molina. La dicotomia público/privado en el pensamiento político ilustrado y liberal. In:

Dialética feminista de la Ilustración. Barcelona: Anthropos. 1994. p. 29-104.

PIMENTA, Fabrícia Faleiros. Políticas feministas e os feminismos na política: o Conselho Nacional dos Direitos da Mulher (1985-2005). 2010.

PIOVESAN, Flávia. A proteção Internacional dos Direitos Humanos das Mulheres. Emerj, Rio de Janeiro, v. 15, n. 57, p. 70-89, jan./mar. 2012. Edição Especial.

PITANGUY, Jacqueline. As mulheres e a Constituição de 1988. In: ÁVILA, Maria Betânia, GOUVEA, Ticiane, XAVIER, Eleny, SILVA, Carmen e PORTELLA, Ana Paula (coord). Mulheres, participação e democracia. 2012. Cadernos de Crítica Feminista, Ano II.

RODRIGUES, Almira et al. Os direitos das mulheres na legislação brasileira pós-constituinte. Letras Livres, 2006.

SARDENBERG, Cecilia M. B. Da Crítica Feminista à Ciência. Uma Ciência Feminista? In: COSTA, Ana Alice Alcântara; SARDENBERG, Cecilia Maria Bacellar (org.). Feminismo, Ciência e Tecnologia, Salvador: Coleção Bahianas, 2002, p. 89-120.

SILVA, Salete Maria da. 0 Legado jus-político do lobby do batom vinte anos depois: a participação das mulheres na elaboração da Constituição Federal. XXI ERED,2008. Disponível em http://www.urca.br/ ered2008/CDAnais/pdf/SD3_files/Salete_Maria_ SILVA_2.pdf. Acesso em: 21 ago. 2018.

SILVA, Salete Maria da. Constitucionalização dos direitos das mulheres no Brasil: um desafio à incorporação da perspectiva de gênero no Direito. Interfaces Científicas -Direito, v. 1, n. 1, p. 59-69, 2012. Disponível em: https://periodicos.set.edu.br/ index.php /direito/article/view/178/76. Acesso em: 21 ago. 2018. 
Data da submissão: 06 de Agosto de 2018

Avaliado em: 23 de Agosto de 2018

Avaliado em: 14 de Setembro de 2018

Aceito em: 17 de Setembro de 2018
1 Mestranda em Estudos Interdisciplinares sobre Gênero, Mulheres e Feminismo pela Universidade Federal da Bahia. Advogada feminista.

E-mail: biancachetto@hotmail.com

2 Mestranda em Estudos Interdisciplinares sobre Gênero, Mulheres e Feminismo pela Universidade Federal da Bahia. Advogada feminista. E-mail: flavia.hardt@gmail.com 